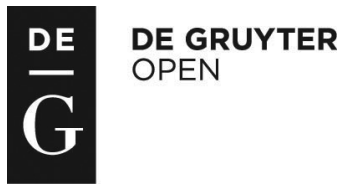

\title{
PERFORMANCE AND SMALL INTESTINE MORPHOLOGY AND ULTRASTRUCTURE OF MALE BROILERS INJECTED IN OVO WITH BIOACTIVE SUBSTANCES*
}

\author{
Joanna Bogucka ${ }^{1}$, Agata Dankowiakowska ${ }^{1}$, Gabriela Elminowska-Wenda ${ }^{1}$, Adrianna Sobolewska ${ }^{1}$ \\ Jan Jankowski², Michał Szpinda ${ }^{3}$, Marek Bednarczyk ${ }^{1}$

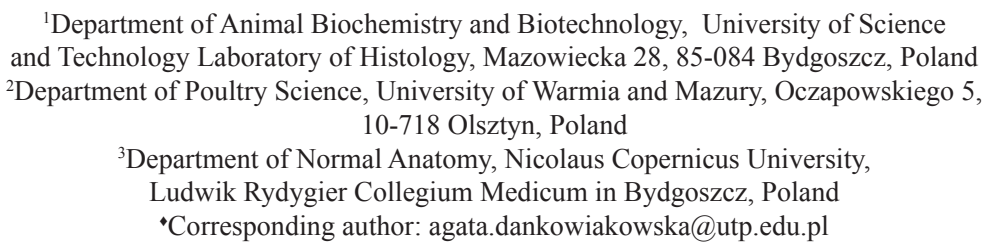

\begin{abstract}
The objective of the present study was to determine the effect of prebiotic and synbiotic preparations injected in ovo on day 12 of embryogenesis on both development of intestinal villi and the number of neutral goblet cells in the small intestine of male broiler chickens on day 35 of rearing. Eggs containing live embryos were randomly separated into five experimental groups (1800 eggs per group), and treated with different bioactive compounds by in ovo injection. The control group (C) was injected with physiological saline. The prebiotic groups (PI and PB) were injected with a solution containing $1.76 \mathrm{mg}$ of inulin or with a solution containing $0.528 \mathrm{mg}$ of $\mathrm{Bi}^{2}$ tos. The injection solution for both synbiotic groups (SI and SB) consisted of $1.76 \mathrm{mg}$ Inulin + $1000 \mathrm{CFU}$ of $L$. lactis spp. lactis 2955 (SL1) or $0.528 \mathrm{mg} \mathrm{Bi}^{2} \mathrm{tos}+1000$ CFU of L. lactis spp. cremoris 477 (SC1). Samples for histological analysis were taken from the three segments of the small intestine: the duodenum, jejunum and ileum. Broiler performance increased in the prebiotic group injected with $\mathrm{Bi}^{2}$ tos when compared to both the control group and the prebiotic group injected with inulin. In relation to other groups, in the duodenum and ileum the highest intestinal villi were observed in chickens with the lowest body weight, i.e. groups $C$ and PI. The smaller surface area of villi was found in the jejunum and ileum in group SB. As far as the jejunum and ileum are concerned, a significantly higher number of goblet cells was noted in groups PB and SB.
\end{abstract}

Key words: broiler chicken, in ovo, bioactive substances, small intestine

*This study was financed by grants No. UMO - 2011/01/B/NZ9/00642 from the National Science Centre in Kraków (Poland), and partially by project "THRIVE RITE - Natural Compounds to enhance Productivity, Quality and Health in Intensive Farming Systems", an EU-funded research collaboration, FP7 Project No. 315198. The research was performed using the equipment purchased within the frame of "Implementation of the 2nd stage of Regional Centre of Innovation", project co-financed by the European Regional Development Fund under the Regional Operational Program for Kuyavian-Pomeranian Voivodeship for the years 2007-2013. 
The small intestine is the place where feed nutrients are both digested and absorbed (Yamauchi et al., 2010; Yang et al., 2013). Simultaneously, the intestinal epithelium acts as a natural immune barrier to pathogenic bacteria and toxins (Pelicano et al., 2005; Xiaofei and Yuming, 2008). After hatching, the digestive system of chicks undergoes a number of morphological changes (an increase in length and density of intestinal villi) and physiological changes (increased production of pancreatic and digestive enzymes) (Yadav et al., 2010). As reported by Uni et al. (1998) and $\mathrm{Hu}$ et al. (2010), the intestinal epithelium of broiler chickens is responsible for the potential growth of chickens after hatching, while the normal morphological and functional development of the intestine leads to an increase in avian body weight (Yamauchi and Tarachai, 2000). The small intestine develops rapidly during the posthatch period, between days 6 and 10 of age. Due to both the intensive proliferation and differentiation of enterocytes - the cells responsible for absorption of nutrients - the weight of the small intestine increases more rapidly than the body weight of the chickens (Mateos et al., 2004). According to Noy and Sklan (1998) and Zavarize et al. (2012), early feeding of chicks immediately after hatching not only accelerates the morphological development of the intestine, but also contributes to the stimulation and development of the digestive tract. This was supported by Geyra et al. (2001) and Uni et al. (1998), who believed late feeding to inhibit the development of the intestinal mucosa, and to adversely affect the production of mucins (Uni et al., $2003 \mathrm{a}, \mathrm{b})$, thereby playing a major role in both the absorptive and barrier functions of the intestine.

Of the three segments of the small intestine, the duodenum develops earlier than the jejunum or the ileum (Uni et al., 1999). The villus area and height rapidly increase during the first two days of life, then the villus growth rate gradually decreases, reaching a plateau between days 5 and 10 post-hatch (Uni et al., 1996). In the intestinal crypts epithelial cells are produced by mitosis. In broilers, proliferation of intestinal epithelial cells in the crypts occurs permanently. In contrast, the cells located along the villi solely proliferate during the first week of life (Zavarize et al., 2012). Most nutrients are absorbed in the proximal part of the small intestine, which results in the decreasing height and area of intestinal villi starting with the duodenum towards the jejunum (Yamauchi et al., 2010).

Intestinal morphology and health are affected by numerous factors, the paramount of which is the animal's diet. Due to both the excessive use of antibiotic growth promoters (AGP) in countries with intensive livestock production and the emergence of antibiotic-resistant strains of bacteria, pharmacological substances have been banned from use (Śliżewska et al., 2006). Increasing attention has recently been paid to a search for new dietary solutions that constitute a safe alternative to antibiotics. The use of natural additives in the form of probiotics, prebiotics and synbiotics has become widespread (Awad et al., 2009).

Water-soluble bioactive substances have also been used in the animal's diet (Śliżewska et al., 2006; Świątkiewicz and Koreleski, 2007; Janocha et al., 2010). An alternative means of giving pro-, pre- and synbiotics is provided by in ovo technology, in which a special needle is used to inject a small amount of substance directly into the bird's egg/embryo during incubation (Bednarczyk et al., 2010). A study by 
Villaluenga et al. (2004) displayed that the optimum time to introduce a prebiotic was day 12 of embryogenesis, because more copious intestinal bifidobacteria were found compared to injection on days 1,8 or 17 . Furthermore, on day 12 the chorioallantoic membrane is completely developed and highly vascularized. At that time, the embryo is surrounded by amniotic fluid, which is in contact with the embryo's digestive tract, thus guaranteeing the transfer of nutrients from the air cell to the intestine. This commonly used method is conducive to stimulate the growth of beneficial gut microflora in chicks, enhance embryo development, improve animal performance, test teratogenic effects, determine embryo sex, and to inject genetically modified cells (Ohta et al., 2001; Villaluenga et al., 2004; Bednarczyk et al., 2010; Zhai et al., $2011 \mathrm{a}, \mathrm{b})$.

Although many modes of action for probiotics, prebiotics and synbiotics exist, they have been not completely understood yet, and so need much debate (Nowak et al., 2010; Dankowiakowska et al., 2013; Khan and Naz, 2013). To date, bioactive substances injected in ovo have been found to exert different effects on production traits and some histological, immune and physiological indicators (Dankowiakowska, 2015; Pruszyńska-Oszmałek et al., 2015; Sławińska et al., 2014 a, b). Since these processes are varied and complex, the present study is to test whether prebiotics and synbiotics administered in ovo on day 12 of incubation can affect intestinal morphology in broiler chickens.

Thus, the objective of the present study was to examine the effect of prebiotic and synbiotic preparations injected in ovo on day 12 of embryogenesis on both the development of intestinal villi and the number of neutral goblet cells in the small intestine of male broiler chickens on day 35 of rearing.

\section{Material and methods}

\section{In ovo treatment}

Hatching eggs were obtained from a 32-week-old flock (Ross 308). Of note, the eggs were collected from the same breeder flock, and were of approximately the same weight of $60 \mathrm{~g}$. Eggs were incubated in a commercial hatchery (Drobex, Solec Kujawski, Poland) in a Petersime incubator. On day 12 of incubation, the eggs were candled, and then infertile ones and those containing dead embryos were discarded. Eggs containing live embryos were randomly separated into five experimental groups (1800 eggs per each group), and treated with different bioactive compounds by in ovo injection. An aqueous solution of an equal volume of $0.2 \mathrm{ml}$ was injected into the air chamber, and the hole in the egg shell was sealed with the use of a dedicated automatic system (Bednarczyk et al., 2011). The control group (C) was injected with physiological saline. The prebiotic groups (PI and PB) were injected with a solution containing $1.76 \mathrm{mg}$ of Inulin (Sigma-Aldrich) or with a solution containing $0.528 \mathrm{mg}$ of $\mathrm{Bi}^{2}$ tos (Clasado Ltd) - commercially developed non-digestive transgalacto-oligosaccharides, respectively. The injection solution for both synbiotic groups (SI and $\mathrm{SB})$ consisted of $1.76 \mathrm{mg}$ Inulin or $0.528 \mathrm{mg} \mathrm{Bi}^{2}$ tos, respectively, enriched with 
different probiotic bacteria. Group SI received 1000 CFU of Lactococcus lactis spp. lactis 2955 (SL1) while group SB received 1000 CFU of Lactococcus lactis spp. cremoris 477 ( $\mathrm{SC1}$ ). The bacteria cultures were prepared as follows: fresh over-night cultures of 477 and 2955 strains in GM17 liquid medium were used. The number of bacteria was estimated at the level of $3 \times 10^{8}$ of living cells. Just before injection, the bacterial cultures were diluted in a prebiotic solution to obtain a bacterial suspension of $1000 \mathrm{CFU}$ in $20 \mathrm{Wl}$. The synbiotics injected in groups SI and SB comprised $180 \mathrm{Wl}$ of the prebiotic solution and $20 \mathrm{Wl}$ of bacterial suspension.

\section{Animals}

After hatching the chickens were sexed and 3250 males with an average initial body weight of $42.0 \mathrm{~g}$ were subjected to raising. The rearing experiment was conducted at the experimental farm of the University of Warmia and Mazury in Olsztyn, and reared for 5 weeks upon the approval of the Polish Local Ethics Committee (No 22/2012, 21.06.2012) and in accordance with the animal welfare recommendations of European Union Directive 86/609/EEC, providing adequate husbandry conditions with continuous monitoring of stocking density, litter, ventilation, and so on. The experiment was performed in 10 reiterations within the groups, each consisting of 650 chickens kept in collective pens (65 chickens/pen). They were fed and watered ad libitum. All the groups received the same diets using a three-phase feeding programme: starter (1-14 days); grower (15-30 days); and finisher (31-34 days). Chickens were weighed on day 34 of age. Feed intake and mortality were monitored systematically. The feed conversion ratio ( $\mathrm{kg}$ feed $/ \mathrm{kg}$ gain) was calculated between weighing periods. The feed conversion ( $\mathrm{kg}$ feed $/ \mathrm{kg}$ live birds) for the entire rearing period was calculated. Furthermore, the European Broiler Index (EBI) was also computed.

FCR $(\mathrm{kg}$ feed $/ \mathrm{kg}$ gain $)=$ cumulative feed intake $(\mathrm{kg}) /$ total weight gain $(\mathrm{kg})$

The EBI was calculated using the following formula (including FCR*):

$$
\mathrm{EBI}=\frac{\text { Body weight }(\mathrm{kg}) \times \text { viability }(\%) \times 100}{\text { Age }(\text { days }) \times \mathrm{FCR}^{*}(\mathrm{~kg} \text { feed } / \mathrm{kg} \text { gain })}
$$

Viability $(\%)=$ chicks remaining at the end of the period (\%).

*FCR - feed consumption/kg of live birds.

The composition and nutritive value of the diets is presented in Table 1.

Table 1. The composition and nutritive value of feed for chickens

\begin{tabular}{l|c|c|c}
\hline & Starter & Grower & Finisher \\
\hline \multicolumn{1}{c|}{} & 2 & 3 & 4 \\
\hline Raw materials (\%) & & & \\
wheat & 26.73 & 29.19 & 30.66 \\
maize & 30.00 & 30.00 & 30.00 \\
\hline
\end{tabular}


Table 1 - contd

\begin{tabular}{lccc}
\hline \multicolumn{1}{c|}{1} & 2 & 3 & 4 \\
\hline extracted soybean meal & 32.50 & 28.20 & 25.33 \\
canola & 5.00 & 6.00 & 7.00 \\
soybean oil & 2.10 & 1.33 & 1.80 \\
lard & - & 2.00 & 2.50 \\
feed salt & 0.30 & 0.30 & 0.28 \\
mel stern & 1.09 & 0.95 & 0.85 \\
phosphate 1-calcium & 1.15 & 0.94 & 0.63 \\
DL-methionine & 0.25 & 0.18 & 0.13 \\
L-lysine & 0.32 & 0.32 & 0.27 \\
L-threonine & 0.06 & 0.09 & 0.05 \\
vitamin-mineral premix ${ }^{1)}$ & 0.50 & 0.50 & 0.50 \\
The nutritional value & & & \\
ME (kcal/kg) & 2980 & 3100 & 3200 \\
total protein (\%) & 22.00 & 20.50 & 19.50 \\
lysine (\%) & 1.35 & 1.25 & 1.15 \\
methionine (\%) & 0.57 & 0.49 & 0.43 \\
methionine + cystine (\%) & 0.95 & 0.85 & 0.78 \\
calcium (\%) & 0.90 & 0.80 & 0.70 \\
phosphorus (\%) & 0.40 & 0.35 & 0.28 \\
sodium (\%) & 0.14 & 0.14 & 0.13 \\
\hline
\end{tabular}

1) $1 \mathrm{~kg}$ of premix contains: Vitamin A - $5000000 \mathrm{IU}$, Vitamin $\mathrm{D}_{3}-1400000 \mathrm{IU}$, Vitamin E - $18200 \mathrm{mg}$, Vitamin $\mathrm{K}_{3}-1200 \mathrm{mg}$, Vitamin $\mathrm{B}_{1}-600 \mathrm{mg}$, Vitamin $\mathrm{B}_{2}-2000 \mathrm{mg}$, Vitamin $\mathrm{B}_{6}-1200 \mathrm{mg}$, Vitamin $\mathrm{B}_{12}-8000 \mathrm{mg}$, biotin $(\mathrm{H})-80000 \mathrm{mg}, \mathrm{Fe}-20000 \mathrm{mg}, \mathrm{Mn}-40000 \mathrm{mg}, \mathrm{Zn}-36000 \mathrm{mg}, \mathrm{Cu}-6000 \mathrm{mg}, \mathrm{I}-400 \mathrm{mg}, \mathrm{Se}-$ $140 \mathrm{mg}$, calcium pantothenate $-4800 \mathrm{~g}$, nicotinic acid - $20000 \mathrm{mg}$, folic acid - $400 \mathrm{mg}$, choline chloride 380 g, phytase -500 FTU.

\section{Histomorphological samples}

Samples for histological analysis (ca. $2 \mathrm{~cm}$ ) were taken immediately after slaughter (day 35) from the three segments of the small intestine: the duodenum, jejunum, and ileum. A total of 150 samples were collected (5 groups $\times 10$ birds $\times 3$ intestinal segments). The samples referred to the midpoint of the duodenum, the midpoint between the entry of the common bile duct and Meckel's diverticulum (jejunum), and the midpoint between Meckel's diverticulum and the ileocecal junction (ileum).

\section{Histomorphological examination}

Particular segments of the small intestine were rinsed with $0.9 \%$ physiological saline, and then fixed with a $4 \% \mathrm{CaCO}_{3}$ buffered formalin solution. The fixed samples were dehydrated, cleared and infiltrated with paraffin in a tissue processor (Thermo Scientific, Waltham, USA), and consecutively embedded in paraffin blocks 
using an embedding equipment (Medite, Germany). The blocks were sectioned at $10-\mu \mathrm{m}$ thickness using a rotary microtome (Thermo Scientific, Waltham, USA), and the sections were sequentially transferred to glass slides being coated with an egg albumin and a glycerine mixture.

\section{Staining methods}

Before staining, the preparations were dewaxed and hydrated, followed by periodic acid-Schiff (PAS) staining to perform morphometric analyses and to stain and count neutral goblet cells.

\section{Histomorphological measurements}

A Carl Zeiss microscope (Jena, Germany) and a computer-based image analysis system of MultiScan 18.03 (Computer Scanning Systems II, Warsaw, Poland) were used to measure the height and width of intestinal villi and the depth of intestinal crypts, and the number of neutral goblet cells was also counted. The height of intestinal villus was measured on 10 villi randomly chosen from the cross-sectional area (CSA). This parameter was measured from the tip to the base of the villus at the opening of the crypt. The villus width was measured at its midpoint. Next, the villus area was calculated using the formula provided by Sakamoto et al. (2000): $(2 \pi) \times$ $(\mathrm{VW} / 2) \times(\mathrm{VH})$, where $\mathrm{VW}=$ villus width, and $\mathrm{VH}=$ villus height. The intestinal crypt depth was defined as the depth of the invagination between adjacent villi, this was measured between 10 adjacent villi (Uni et al., 1998). The number of PAS-positive cells was counted per $\mathrm{mm}^{2}$ of villi area.

\section{Statistics}

The results were subjected to one-way analysis of variance using STATISTICA AXAP, version 10.0 MR1. Arithmetic means ( $\bar{x})$ and standard errors of the mean (SEM) were calculated. Significant differences between groups were analysed with the use of Duncan's multiple range test.

\section{Results}

\section{BW, FCR, EBI}

The body weight of broiler chickens on day 34 (one day before slaughter) is presented in Table 2. The highest body weight was found in the group of chickens injected in ovo with the prebiotic $\mathrm{Bi}^{2}$ tos, and the lowest in both the control group (C) and the group injected with the prebiotic inulin $(\mathrm{PI})(\mathrm{P}<0.01)$.

Between days 1 and 34 of age, the feed conversion ratio (FCR) ranged from $1.54 \pm 0.05$ to $1.56 \pm 0.05$ while the EBI oscillated between $378 \pm 35$ and $389 \pm 25$ (Table 2). No statistically significant differences were found between the analysed groups of chickens for either FCR or EBI (Pruszyńska-Oszmałek et al., 2015). 
Table 2. Body weight, FCR, EBI and hatchability of chickens on day 34 in relation to bioactive substances injected in ovo on day 12 of incubation

\begin{tabular}{lcc|c|c}
\hline Group & Body weight $(\mathrm{kg})$ & FCR & EBI & Hatchability \\
\hline $\mathrm{C}$ & $2.06 \mathrm{C} \pm 0.21$ & $1.56 \pm 0.05$ & $378 \pm 35$ & $97.72 \mathrm{a} \pm 1.90$ \\
PI & $2.06 \mathrm{C} \pm 0.23$ & $1.54 \pm 0.05$ & $379 \pm 23$ & $89.58 \mathrm{~b} \pm 1.71$ \\
PB & $2.14 \mathrm{~A} \pm 0.23$ & $1.55 \pm 0.04$ & $389 \pm 25$ & $91.82 \mathrm{ab} \pm 3.01$ \\
SI & $2.12 \mathrm{AB} \pm 0.24$ & $1.56 \pm 0.06$ & $387 \pm 36$ & $92.42 \mathrm{ab} \pm 2.76$ \\
SB & $2.09 \mathrm{BC} \pm 0.25$ & $1.55 \pm 0.03$ & $380 \pm 25$ & $91.43 \mathrm{ab} \pm 6.68$ \\
SEM & 0.006 & 0.007 & 7.711 & 0.811 \\
\hline
\end{tabular}

C - Control, PI - Prebiotic 1 (inulin), PB - Prebiotic 2 (Bi ${ }^{2}$ tos), SI - Synbiotic 1 (inulin + Lactococcus lactis subsp. lactis 2955), SB - Synbiotic 2 ( $\mathrm{Bi}^{2}$ tos + Lactococcus lactis subsp. cremoris 477$)$.

$\mathrm{A}, \mathrm{B}, \mathrm{C}-$ difference $(\mathrm{P} \leq 0.01)$ between treatments (vertical).

$\mathrm{a}, \mathrm{b}$ - difference $(\mathrm{P} \leq 0.05)$ between treatments (vertical).

FCR - Feed Conversion Ratio.

EBI - European Broiler Index.

\section{Morphology of the small intestine}

\section{Morphometric parameters}

Morphometric parameters of the villi (height, width, surface area) and the depth of crypts in the three segments of the small intestine (duodenum, jejunum and ileum) in 35-day-old chickens have been presented in Table 3. In the duodenum, the highest intestinal villi in relation to the other groups were observed in chickens with the lowest body weight, i.e. groups $\mathrm{C}$ and PI $(\mathrm{P}<0.01)$. The widest villi in the duodenum were found in groups SI and SB, and differed significantly in relation to group $\mathrm{C}$ $(\mathrm{P}<0.05)$. Despite the variation in the villus height, no significant differences were found for the surface area of duodenal villi.

In the group injected in ovo with the prebiotic $\mathrm{Bi}^{2}$ tos, the crypt depth was the greatest and differed significantly in relation to the control group $(\mathrm{P}<0.01)$. The analysed pre- and synbiotics exerted no significant effect on the height of the jejunal villus in the chicken. The surface area of jejunal villi showed variation due to the differences in the villus width in the studied birds. The greatest surface area of jejunal villi was found in group $\mathrm{C}$, and differed significantly when compared to group $\mathrm{SB}(\mathrm{P}<0.01)$. In this segment of the small intestine, the intestinal villus depth ranged from $156.29 \mu \mathrm{m}$ (group PI) to $180.53 \mu \mathrm{m}$ (group SI) $(\mathrm{P}<0.01)$. The highest ileal villi (like duodenal villi) were observed in two groups of chickens with the lowest body weight (groups PI and C). These groups differed significantly in relation to groups $\mathrm{PB}$ and $\mathrm{SB}(\mathrm{P}<0.05)$. In relation to the two remaining groups, the smallest height and width of the villi in group SB contributed to a considerable decrease in their surface area $(\mathrm{P}<0.01)$.

\section{Goblet cells}

On day 35 the number of goblet cells per $\mathrm{mm}^{2}$ of the duodenal villus area (Figure 1) was the highest in group $\mathrm{C}$, and the lowest in group SI, though the differences were not significant. Concerning the jejunum, a significantly higher number of goblet cells was visualized in groups $\mathrm{PB}$ and $\mathrm{SB}$, when compared to group $\mathrm{C}(\mathrm{P}<0.05)$. In the ileum, significantly fewer goblet cells were observed in group SI in relation to groups $\mathrm{PB}$ and SB (Figures 1-3). 


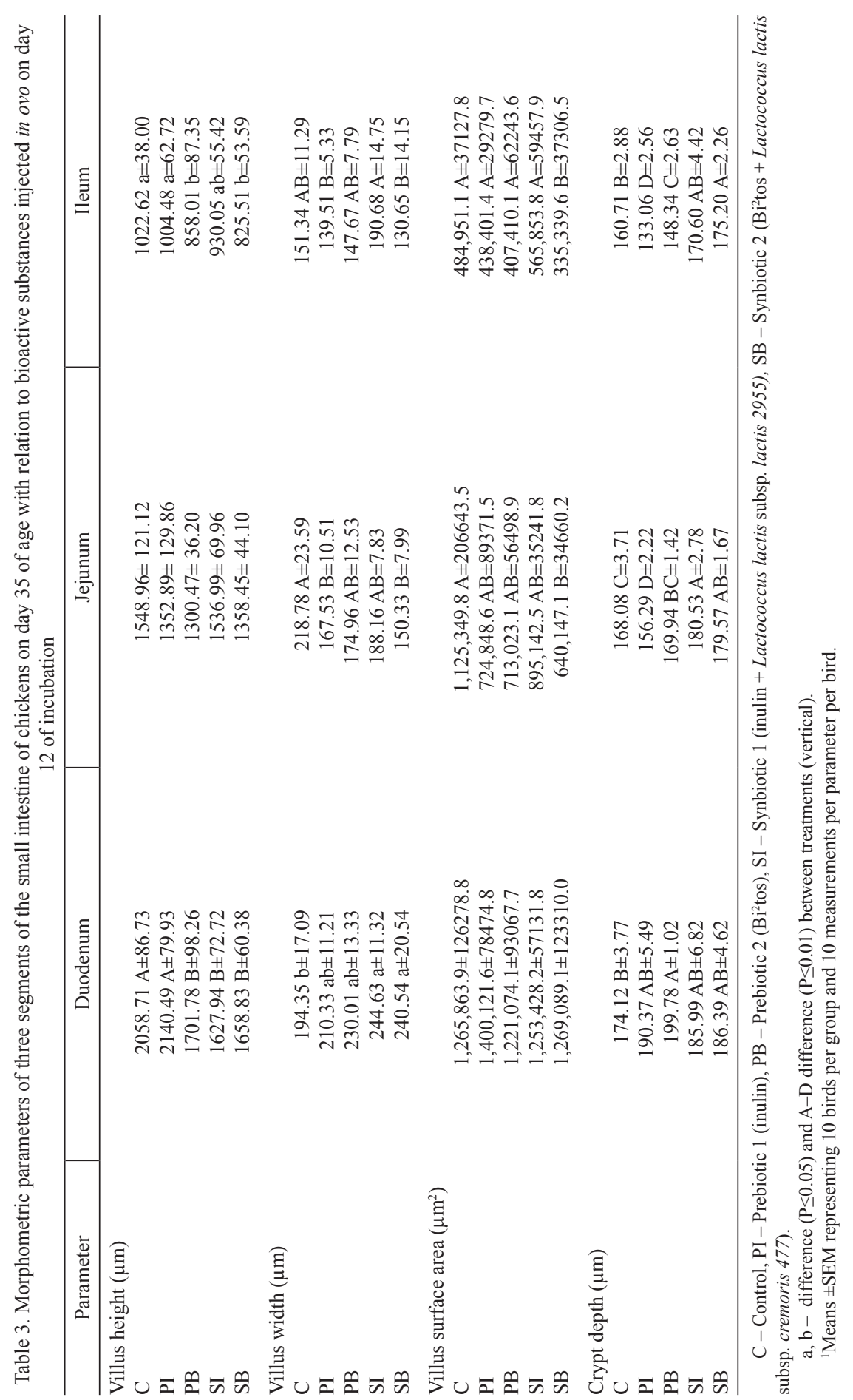




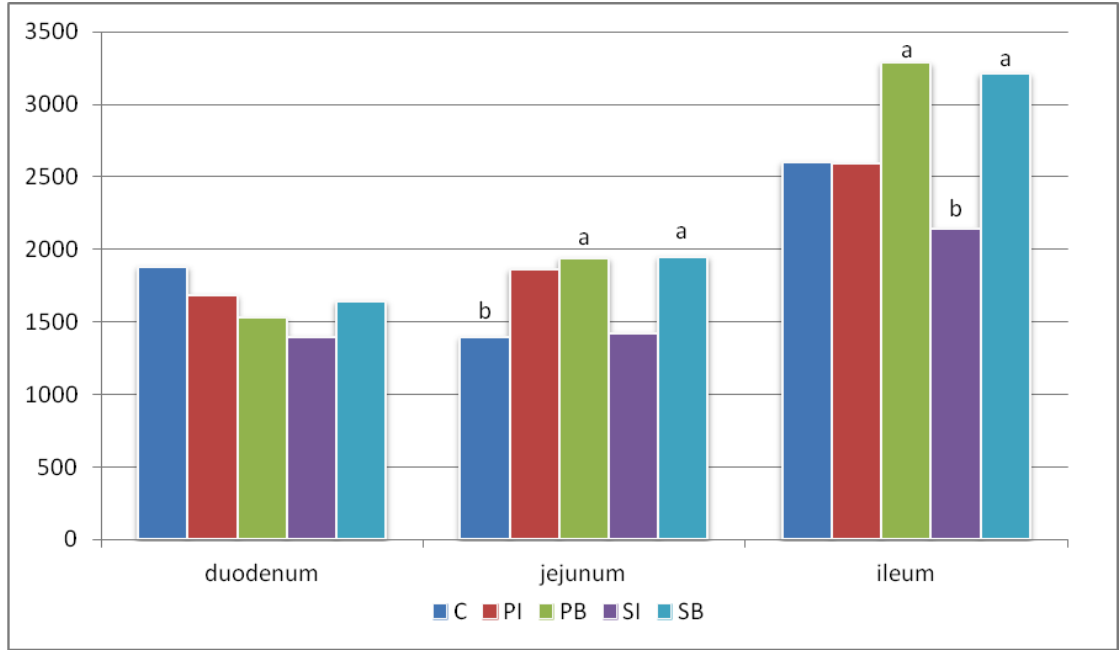

C - Control, PI - Prebiotic 1 (inulin), PB - Prebiotic 2 ( $\mathrm{Bi}^{2}$ tos), SI - Synbiotic 1 (inulin + Lactococcus lactis subsp. lactis 2955), SB - Synbiotic 2 ( $\mathrm{Bi}^{2}$ tos + Lactococcus lactis subsp. cremoris 477). $\mathrm{a}, \mathrm{b}$ - difference $(\mathrm{P} \leq 0.05)$ between treatments.

Figure 1. The number of neutral goblet cells on the surface area of $1 \mathrm{~mm}^{2}$ of intestinal villi in 35 -day-old chickens in relation to bioactive substances injected in ovo on day 12 of incubation

\section{Discussion}

Chicken hatchability is influenced by numerous factors. Besides brood technology, hatchability depends on the quality of the shell (thickness, porosity, resistance to crushing) and the egg content, and indirectly on welfare, nutrition and health of the herd (Krawczyk et al., 2012).

In our study, the smallest percentage of hatched chicks was characteristic of the group injected with inulin (PI), which differed significantly from the control group (Table 2). A similar hatchability in the prebiotic group (PB) was obtained by Bednarczyk et al. (2016). However, hatchability in our study was high (89.58-92.72\%), and comparable to that reported by Krawczyk et al. (2012), based on optimally equipped hatcheries. According to research by Zhai et al. (2011 a), nutrients given in ovo did not affect hatchability of chickens. Cox et al. (1992) found that the injection into the egg air cell, as compared to injection into the amniotic fluid was more efficient and did not reduce hatchability. Edens et al. (1997) reported that the site of administration of substances did not have a significant effect on chicken's hatchability. As compared to Bacillus subtilis, bacterium Enterococcus faecium is more effective for injections. Furthermore, chicken's hatchability in the control group was the highest, reaching even 100\% (De Oliveira et al., 2014). As stated by Shashidhara and Devegowda (2003), addition of MOS (mannanooligosaccharides) to the diet exerted a positive impact on the hatchability of Cobb broilers. Plausible differences between 
particular results might result from numerous factors such as the site of injection, type, properties and doses of substances, and also from technology of egg incubation (Bednarczyk et al., 2011; De Oliveira et al., 2014).

Bioactive substances used in poultry production contribute to a general improvement in both the health of birds, and an increase in meat and egg production, improve the FCR, and exert a positive effect on intestinal histomorphology (Rahimi et al., 2009). In the material under examination, the prebiotics and synbiotics influenced significantly on the production parameters (body weight, FCR, EBI). The highest body weight was found in the group injected with the prebiotic $\mathrm{Bi}^{2}$ tos. The lowest body weight was observed in control chickens and in birds from the group supplemented with inulin. It is noteworthy that similar results were obtained by Awad et al. $(2008,2009)$. According to these authors, a dietary synbiotic was responsible for a significant increase in body weight of chickens on day 35 of rearing. However, these body weights were considerably lower than those obtained in our study. Similarly to the study by Swamy and Upendra (2013), a probiotic-enriched feed significantly contributed to the body weight of 35-day-old birds. Again, the mean body weights were lower than those obtained in the present study. Pilarski et al. (2005) concluded that supplemental RFO (raffinose family oligosaccharides) and FOS (fructooligosaccharides), injected in ovo on day 12 of incubation, caused an increase in body weight of broiler chickens on day 42. Comparable results were also obtained by Bednarczyk et al. (2011), who found the prebiotic RFO injected in ovo to significantly increase chicken's body weight of Ross 708 chickens on day 42. The higher mean body weight was also found by Kornasio et al. (2011), who injected a carbohydrate solution into the amnion on day 18 of embryogenesis. In a study by Maiorano et al. (2012), in groups injected in ovo with a prebiotic (RFO) and synbiotics (RFO + 1,000 cfu of Lactococcus lactis ssp. lactis SL1 and RFO + 1,000 cfu of Lactococcus lactis ssp. cremoris IBB SC1), the mean body weights of chickens were higher than those in the control group. According to Dono et al. (2014), birds with higher rates of growth utilized nutrients more efficiently. However, this depends on the conditions of the intestinal environment that may promote both development and proliferation of beneficial microflora.

In poultry production, broiler feeding accounts for about $70 \%$ of the total production costs (Willems et al., 2013). Feed utilization and conversion efficiency by the bird are important determinants of production profitability. In our study, the FCR value on day 34 of rearing was comparable to the findings of Shabani et al. (2012), referring to birds fed on probiotic substances. In both experiments, the FCR value was higher in the control group than in the experimental one. Of note, disparate results were obtained by Biernasiak and Śliżewska (2009), who reported higher FCR in the experimental group. In a study by Jang et al. (2004), who supplemented the diet with $0.1 \%$ lactic acid, the FCR in 35-day-old chickens was higher than in our study, but its value was still highest in the control group. Bednarczyk et al. (2016) showed the increasing trend for the FCR. This might be due to metabolic properties related to increased activities of digestive enzymes (Pruszyńska-Oszmałek et al., 2015). On day 42 of growth, standard broiler yield is $2.5 \mathrm{~kg}$ of live weight and the FCR value is 1.72 (Creswell, 2005). As reported by Nabizadeh (2012), $0.5 \%$ and $1 \%$ inulin sup- 
plements in feed reduced the FCR, whose value reached 1.76 and 1.67 , respectively, when compared to that of 1.79 in the control group. However, the effect of bioactive substances on the feed conversion ratio is still inconsistent (Ahmad, 2006). Mohan et al. (1996) and Chiang and Esieh (1995) reported the beneficial effect of probiotics on both weight gains and body weight to be only noticeable between days 28 and 42 , and in the case of the FCR between days 21 and 42 (Fritts et al., 2000). This view was shared by Jin et al. (1996), who used probiotics such as Lactobacillus (LAB) and Bacillus subtilis in their experiment. In turn, other authors suggested that probiotics exerted no effect on the feed conversion ratio (Panda et al., 1999; Ergun et al., 2000; Panda et al., 2000).

Poultry rearing efficiency is evaluated using the European Broiler Index (EBI). In our study, the EBI was the highest in the experimental groups, in which a prebiotic (PB) and synbiotics (SI and SB) were used. The value of this indicator was considerably higher than that reported by Biernasiak and Śliżewska (2009) for a probiotic preparation, and comparable to that reported by Brzóska (2007), who investigated the effect of a synbiotic (LAB + MOS). Furthermore, similar results to ours were observed by Janocha et al. (2010).

The effect of pro-, pre- and synbiotics on bird growth, overall yield, and carcass yield is not fully understood. As has already been noted, there are many modes of action of bioactive substances which are not completely obvious. In our study, we determined the effect of bioactive substances on the microstructure of three intestinal segments in 35-day-old chickens expressed by the following three parameters: villus height, surface area, and crypt depth. Of all the groups injected with bioactive substances, in group PI there was a significant effect of inulin on an increase in villus height in the duodenum and ileum. In research by Nabizadeh (2012), 1\% addition of inulin to feed did not affect the height of intestinal villi, crypt depth in both the duodenum and jejunum. In the study by Awad et al. (2009), neither probiotic nor synbiotic substances had a significant effect on the duodenal villus height. In the present study, the duodenal villus height in chickens from groups injected with synbiotics was similar to the findings reported by Awad et al. $(2008,2009)$ and Houshmand et al. (2012). As regards the ileum, the villus height exceeded the values obtained by other authors (Awad et al., 2008, 2009; Houshmand et al., 2012). As reported by Jin et al. (1996), the lengthening of intestinal villi could be affected by an increased concentration of pancreatic amylase. The highest concentration of this enzyme was observed in group PI on day 21, while in groups SI and SB the high content of pancreatic amylase persisted until day 34 of age (Pruszyńska-Oszmałek et al., 2015). Of note, an increase in intestinal villus length is correlated to the enhanced digestive and absorptive functions of the intestine, leading to an increased absorptive area and an increased activity among intestinal brush border enzymes (Pluske et al., 1996). In accordance with Awad et al. (2009), addition of bioactive substances activated the absorptive surface area of the intestine. Prebiotic $\mathrm{Bit}^{2} \mathrm{Os}$ as well as inulin and $\mathrm{Bit}^{2} \mathrm{os}$ used in combination with a probiotic increased the depth of intestinal crypts in different segments of the intestine. According to Awad et al. (2008, 2009), intestinal crypts were much shallower than in the present study. Anatomical changes in intestinal morphology, namely the shortening of the villi and the deepening of the crypts were 
influenced by the presence of toxins. It is noteworthy these changes might cause negative effects in the form of diarrhoea, compromised resistance and yield of the birds (Xu et al., 2003; Awad et al., 2009).

Among physical barriers that protect the organism from pathogens and toxins, apart from low $\mathrm{pH}$ and proteases present in gastric and pancreatic juice, at first should be mentioned intestinal mucus (Fisinin and Surai, 2013), which coats the mucosa in the gastrointestinal tract from the oral cavity to the rectum, and serves as the primary line of defence against foreign bacteria and other pathogens that penetrate the intestinal lumen. The intestinal mucus is predominantly composed of mucin glycoproteins, which are synthesized and secreted by goblet cells (Forstner and Forstner, 1994; Uni et al., 2003 b). Goblet cells, named after their distinctive shape, are extremely specialized and polarized intestinal epithelial cells. They are produced through mitosis from pluripotent stem cells at the base of intestinal crypts (Uni et al., $2003 \mathrm{~b}$ ). Goblet cells are short-lived and constantly undergo replacement. They migrate from the base of the crypt towards the villus tip where they are sloughed off. The whole process takes 2 to 3 days (Uni et al., 2003 b). During the first 3 days post-hatch the chicken's intestine mainly contains acid mucins, but over subsequent days the proportions of acid and neutral mucins equalize. As reported by Uni et al. (2003 b), the number of goblet cells in the intestine of broiler chickens increased from the duodenum to the jejunum. Mucin is formed from different sugar molecules; the main glycoprotein is MUC2, whereas MUC3A and B are two membrane isoforms. Goblet cells also produce metals cations such as iron, zinc, lithium and calcium, as well as lectins (Dibner and Richards, 2004). As reported by Forder et al. (2007), a chemical composition of mucus is essential for the establishment of the intestinal barrier. In addition to defensive functions, mucins serve a major role in the transportation of substances from the intestinal lumen to epithelial microvilli (Duritis et al., 2013). The number of goblet cells and mucus composition are also considerably affected by the animal's diet (Dibner and Richards, 2004).

In the group injected with inulin (PI), the number of neutral goblet cells in the duodenum of birds on day 35 of rearing was comparable with the findings of Baurhoo et al. (2009), who supplemented bird diets with $0.5 \%$ mannanoligosaccharides (MOS). The highest number of goblet cells in the duodenum was found in group $\mathrm{C}$ and the lowest in the synbiotic supplemented group SI. From proximal to distal in the intestine, the number of goblet cells in both groups increased. However, the number of goblet cells in the jejunum was lower, while in the ileum was higher, when compared to the study by Baurhoo et al. (2009). With regard to the jejunum, a significant effect on the increasing number of cells was exerted by the prebiotic $\mathrm{Bi}^{2}$ tos and the synbiotic with the prebiotic $\mathrm{Bi}^{2}$ tos. A similar trend was observed for the ileum, in which significantly fewer goblet cells were found in group SI in relation to groups $\mathrm{PB}$ and SB. The increased number of PAS-positive cells might be typical of the presence of pathogens in the chicken's small intestine (Forder et al., 2007). Runnels et al. (1980) and Dean-Nystrom and Samuel (1994) reported that an increase in neutral mucin production is a kind of defence mechanism against pathogenic bacteria.

As reported by Aliakbarpour et al. (2012), supplementation of the broiler's diet with the probiotics of $B$. subtilis and LAB influences the expression of MUC2 genes. 
In both the study of these authors and ours, PAS-positive goblet cells in the jejunum were more numerous in the experimental groups than in the control group. In addition to that, in group SI which was supplemented with the probiotic LAB and the prebiotic inulin, the number of goblet cells was similar to the results reported by Aliakbarpour et al. (2012), who used the probiotic LAB. Tellez et al. (2006) and Mountzouris et al. (2010) provided evidence that the use of probiotics exerted a positive effect on the intestinal ecosystem and its integrity, the intestinal barrier, digestion, and the immune functions of the intestine, which corresponded to better health for broiler chickens. The dietary addition of prebiotic MOS resulted in better morphological development of the intestine by both the increasing villus length and the number of goblet cells (Baurhoo et al., 2009). Prebiotics, including inulin, had a positive effect on the growth of intestinal bifidobacteria and lactic acid bacteria (LAB) (Yusrizal and Chen, 2003; Xu et al., 2003). Smirnov et al. (2006) reported that probiotics, due to their positive effects on intestinal microflora, influenced the synthesis and/or degradation of mucins produced by goblet cells. LAB bacteria might bind to enterocyte receptor sites and regulate MUC2 secretion (Mack et al., 1999; Mattar et al., 2002).

\section{Conclusions}

It is concluded from the present study that the commercially produced transgalactooligosaccharide $\mathrm{Bi}^{2}$ tos, injected in ovo on day 12 of embryogenesis, increased the body weight of chickens on day 35 of rearing. No effect of the bioactive substances on the FCR and EBI was found. In addition, the prebiotics and synbiotics exerted a significant effect on the small intestine morphology in chickens. A positive effect on microstructural characteristics of the small intestine was exerted by inulin as it increased the villus height in the duodenum and ileum in comparison to other substances. The absorptive area of the duodenum increased in response to inulin supplementation. In the jejunum and ileum, the villus surface area was negatively affected only by the synbiotic with the $\mathrm{Bit}^{2} \mathrm{os}$ preparation, but other injected substances had a positive effect on the absorptive area of the intestine. The crypts, in which intestinal epithelial cells are intensively regenerated, were observed to deepen in chickens supplemented with the prebiotic $\mathrm{Bit}^{2}$ os (duodenum), the synbiotic with inulin (jejunum) and the synbiotic with $\mathrm{Bit}^{2}$ os preparation (ileum). No significant effect of the prebiotics and synbiotics on the number of goblet cells in the duodenum was observed. Both in the jejunum and ileum, the prebiotic $\mathrm{Bit}^{2}$ os with the synbiotic contributed to an increase in the number of PAS-positive goblet cells.

\section{Acknowledgments}

We hereby express our gratitude to Goerge Tzortis (Clasado Ltd., Malta) for providing us with the commercial prebiotic $\mathrm{Bi}^{2}$ tos. Jacek Bardowski and Joanna Żylińska from Institute of Biochemistry and Biophysics, Polish Academy of Sciences in Warsaw are kindly acknowledged for the bacteria strains. 


\section{References}

A h m a d I. (2006). Effect of probiotics on broiler performance. Int. J. Poult. Sci., 5: 593-597.

A liakbarpour H.R., Chamani M., Rahimi G., S ad eghi A.A., Qujeq D. (2012). The Bacillus subtilis and lactic acid bacteria probiotics influences intestinal mucin gene expression, histomorphology and growth performance in broilers. Asian-Aust. J. Anim. Sci., 25: 1285-1293.

Aw a d W., G har e e b K., B ö h m J. (2008). Intestinal structure and function of broiler chickens on diets supplemented with a synbiotic containing Enterococccus faecium and oligosaccharides. Int. J. Mol. Sci. 9: 2205-2216.

Aw a d W.A., Ghare e b K., A bde l-R a he e m S., B ö h m J. (2009). Effects of dietary inclusion of probiotic and synbiotic on growth performance, organ weights, and intestinal histomorphology of broiler chickens. Poultry Sci., 88: 49-56.

B a u rh o o B., F e rk et P.R., Z h a X. (2009). Effects of diets containing different concentrations of mannanoligosaccharide or antibiotics on growth performance, intestinal development, cecal and litter microbial populations, and carcass parameters of broilers. Poultry Sci., 88: 2262-2272.

Bednarczyk M., Brzezińska J., Sławińska A., Siwek M., Urbanowski M., Kas perczyk K. (2010). In ovo technology - a tool in modern poultry prophylaxis (in Polish). Biotechnologia, 88: 109-118.

Bednarczyk M., Urbanowski M., Gulewicz P., Kasperczyk K., Maiorano G., $\mathrm{S} z w a c z k o w s k i \mathrm{~T}$. (2011). Field and in vitro study on prebiotic effect of raffinose family oligosaccharides in chickens. Bull. Vet. Inst. Puławy, 55: 465-469.

Bednarczyk M., Stadnicka K., Kozłowska I., Abiuso C., Tavaniello S., Dankowiakowska A., Sławińska A., Maiorano G. (2016). Influence of different prebiotics and mode of their administration on broiler chicken performance. Animal, doi:10.1017/ S175173111600017

Biernasiak J., Śliżewska K. (2009). The effect of a new probiotic preparation on the performance and faecal microflora of broiler chickens. Med. Weter., 54: 525-531.

B r zó s k a F. (2007). Effectiveness of organic acid and synbiotic in broiler chicken feeding (in Polish). Med. Weter., 63: 831-835.

Chi ang S.H., E si e h W.M. (1995). Effect of direct-fed microorganisms on broiler growth performance and litter ammonia level. Asian-Aust. J. Anim. Sci., 8: 159-162.

Cox N.A., B a il e y J.S., B lanke n ship L.C., Gild e r s le e ve R.P. (1992). In ovo administration of a competitive exclusion culture treatment to broiler embryos. Poultry Sci., 71: 1781-1784.

Creswe 11 D. (2005). The nutritional requirements of today's broiler. Asian Poultry Magazin, May, $18-21$.

Dankowiakowska A., Kozłowska I., B ednarczyk M. (2013). Probiotics, prebiotics and synbiotics in poultry - mode of action, limitation, and achievements. JCEA, 14: 467-478.

D e a n- N y s t r o m E.A., S a m u e 1 J.E. (1994). Age-related resistance to 987P fimbria-mediated colonization correlates with specific glycolipid receptors in intestinal mucus in swine. Infect. Immun., 62: 4789-4794.

De Oliveira J.E., Van der Hoeven-Hangoor E., Van de Linde I.B., Montijn R.C., Van de r Vos s e n J.M.B.M. (2014). In ovo inoculation of chicken embryos with probiotic bacteria and its effect on posthatch Salmonella susceptibility. Poultry Sci., 93: 818-829.

Dibne r J.J., Richard s J.D. (2004). The digestive system: challenges and opportunities. J. Appl. Poultry Res., 13: 86-93.

D o n o N.D., S p ark s N.H., O lu k o s i O.A. (2014). Association between digesta pH, body weight, and nutrient utilization in chickens of different body weights and at different ages. J. Poultry Sci., 51: 180-184.

Duritis I., Mugurevics A., Mancevica L. (2013). Distribution and characterization of the goblet cells in the ostrich small intestine during the pre- and posthatch period. Vet. Med. Zoot., 63: $23-28$

E d e n s F., P i e r c e J. (1997). Nutrigenomics: Implications for prebiotics and intestinal health. Proc. Alltech Technical Symposium, Arkansas Nutrition Conference, Rogers.

Ergun A., Ya lc in S., S a c a kli P. (2000). The usage of probiotic and zinc bacitracin in broiler rations. Ankara Universitesi Veteriner Fakultesi Dergisi, 47: 271-280. 
F i s in in V.I., S u r a i P. (2013). Gut immunity in birds: Facts and reflections. Agric. Biol., 4: 3-25.

Forder R.E.A., How a rth G.S., Tivey D.R., Hughes R.J. (2007). Bacterial modulation of small intestinal goblet cells and mucin composition during early posthatch development of poultry. Poultry Sci., 86: 2396-2403.

F or stne r J.F., F or s tn er G.G. (1994). Gastrointestinal mucus. In: Physiology of the Gastrointestinal Tract, P. Leonard, R. Jonhston (eds). Raven Press, New York, 3rd ed., pp. 1255-1283.

Fritts C.A., Kersey J.H., Motl M.A., Kroger E.C., Yan F., S i J., Jiang Q., Compos M.M., Waldroup A.L., Waldroup P.W. (2000). Bacillus subtilis C-310 (calsporin) improves live performance and microbiological status of broiler chicken. J. Appl. Poultry Sci., 9: $149-155$.

Ge y ra A., Uni Z., Sklan D. (2001). The effect of fasting at different ages on growth and tissue dynamics in the small intestine of the young chick. Br. J. Nutr., 86: 53-61.

Hou shmand M., A zhar K., Zulkifili I., B ejo M.H., Ka m y ab A. (2012). Effects of prebiotics, protein level, and stocking density on performance, immunity, and stress indicators of broilers. Poultry Sci., 91: 393-401.

H u X.F., Gu o Y.M., Hu a n g B.Y., Zhang L.B., B un S., Li u D., Long F.Y., Li J.H., Yang X., J i a o P. (2010). Effect of corticosterone administration on small intestinal weight and expression of small intestinal nutrient transporter mRNA of broiler chickens. Asian-Aust. J. Anim. Sci., 23: $175-181$.

Jang I.S., Ko Y.H., Yang H.Y., Ha J.S., Kim J.Y., Kang S.Y., Yoo D.H., Nam D.S., K i m D.H., L e e C.Y. (2004). Influence of essential oil components on growth performance and the functional activity of the pancreas and small intestine in broiler chickens. Asian-Aust. J. Anim. Sci., 17: 394-400.

J a n o cha A., M i l c z a re k A., O s e k M., T ury k Z. (2010). Effectiveness of probiotic bacteria and prebiotic in broiler chicken feeding (in Polish). Acta Sci. Pol., Zootech., 9: 21-30.

J in L.Z., Ho Y.W., A b dulla h N., J a la lu d in S. (1996). Influence of dried Bacillus subtilis and lactobacilli cultures on intestinal microflora and performance in broilers. Asian-Aust. J. Anim. Sci., 9: 397-404.

K h a n R.U., N a z S. (2013). The applications of probiotics in poultry production. World's Poultry Sci., J., 69: 621-631.

Kornas i o R., Ha levy O., K e d a r O., Un i Z. (2011). Effect of in ovo feeding and its interaction with timing of first feed on glycogen reserves, muscle growth, and body weight. Poultry Sci., 90: $1467-1477$.

Krawczyk J., Pu chała M., O brzut J. (2012). Hatchability in laying hen flocks under the conservation programme (in Polish). Wiad. Zoot., L, 4: 41-46.

M a c k D.R., M i chail S., We i S., M c D o u gall L., Holling s w or th M.A. (1999). Probiotics inhibit enteropathogenic $E$. coli adherence in vitro by inducing intestinal mucin gene expression. Am. J. Physiol., 276: 941-950.

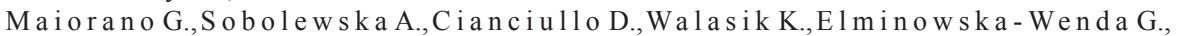
Sławińska A., Tavaniello S., Żylińska J., Bardowski J., Bednarczyk M. (2012). Influence of in ovo prebiotic and synbiotic administration on meat quality of broiler chickens. Poultry Sci., 91: 2963-2969.

Mateos G., Gonzales-Alvarado J.M., Lazaro R. (2004). Facing the realities of poultry health and performance without antibiotics in Europe. Proc. International Feed Industry Symposium, Lexington, USA, pp. 69-79.

Mattar A., Teitelbaum D.H., Drongowski R., Yongy F., Harmon C., Coran A. (2002). Probiotics up-regulate MUC-2 mucin gene expression in a Caco-2 cell-culture model. Pediatr. Surg. Int., 18: 586-590.

Mohan B., K a drivel R., N at araja n A., B has k a ran M. (1996). Effect of probiotic supplementation on growth, nitrogen utilization and serum cholesterol in broilers. Br. Poultry Sci., 37: $395-401$.

Mountzouris K.C., Tsitrsikos P., Palamidi I., Arvaniti A., Mohnl M., Schatzma y r G., F e ger o s K. (2010). Effect of probiotic inclusion levels in broiler nutrition on growth performance, nutrient digestibility, plasma immunoglobulins, and cecal microflora composition. Poultry Sci., 89: 58-67. 
$\mathrm{Nabizadeh} \mathrm{A.} \mathrm{(2012).} \mathrm{The} \mathrm{effect} \mathrm{of} \mathrm{inulin} \mathrm{on} \mathrm{broiler} \mathrm{chicken} \mathrm{intestinal} \mathrm{microflora,} \mathrm{gut} \mathrm{morphology,}$ and performance. J. Anim. Feed Sci., $21: 725-734$.

Nowak A., Śliżewska K., Libudzis z Z. (2010). Probiotics - history and mechanisms of their effect (in Polish). Żywność. Nauka. Technologia. Jakość, 4: 5-19.

N o y Y., S k 1 a n D. (1998). Yolk utilization in the newly hatched poult. Brit. Poultry Sci., 39: 446-451.

O h t a Y., Kidd M., I s hib a sh i T. (2001). Embryo growth and amino acid concentration profiles of broiler breeder eggs, embryos, and chick after in ovo administration of amino acids. Poultry Sci., 80: $1430-1436$.

P a n d a A.K., R a o S.V.R., R e d d y M.R., P r a h a r a j N.K. (1999). Effect of dietary inclusion of probiotic on growth, carcass traits and immune response in broilers. Ind. J. Poultry Sci., 34: 343-346.

P and a A.K.,. R eddy M.R., R a o S.V.R., R a j u M.V.L.N., Prah ar aj N.K. (2000). Growth, carcass characteristics, immunocompetences and response to Escherichia coli of broilers fed on diets with various levels of probiotic. Arch. Geflugelkd., 64: 152-156.

Peli cano E., S ouza P., S ouza H., Figue iro D., Boiago M., Carvalho S., Bordon V. (2005). Intestinal mucosa development in broiler chickens fed natural growth promoters. Braz. J. Poultry Sci., 7: 221-229.

Pilarski R., Bednarczyk M., Lisowski M., Rutkowski A., Bernacki Z., Ward eńs k a M., G u le w i c z K. (2005). Assessment of the effect $\alpha$-galactosides injected during embryogenesis on selected chicken traits. Folia Biol. (Kraków), 53: 13-20.

Pluske J.R., Thompson M.J., A tw o od C.S., B ird P.H., Willi a m s I.H., Hartmann P.E. (1996). Maintenance of villus height and crypt depth, and enhancement of disaccharide digestion and monosaccharide absorption, in piglets fed on cows' whole milk after weaning. Brit. J. Nutr., 76: 409-422.

Pruszyńska-Oszmałek E., Kołodziejski P.A., Stadnicka K., S as sek M., Chałupka D., Kuston B., Nogowski L., Maćkowiak P., Maiorano G., Jankowski J., $\mathrm{B}$ e d $\mathrm{n}$ a r $\mathrm{zy} \mathrm{k}$ M. (2015). In ovo injection of prebiotics and synbiotics affects the digestive potency of the pancreas in growing chickens. Poultry Sci., 94: 1909-1916.

R a h im i S., Grime s J.L., F le t ch e r O., O vi e d o E., S h eld o n B.W. (2009). Effect of a directfed microbial (Primalac) on structure and ultrastructure of small intestine in turkey poults. Poultry Sci., 88: 491-503.

R u n ne ls P.L., M o on H.W., S c hn e i d e r R.A. (1980). Development of resistance with host age to adhesion of K99+ Eschericha coli to isolated intestinal epithelial cells. Infect. Immun., 28: 298-300.

Sakamoto K., Hirose H., Onizuka A., Hayashi M., Futamura N., Kawamura Y., E zaki T. (2000). Quantitative study of changes in intestinal morphology and mucus gel on total parenteral nutrition in rats. J. Surg. Res., 94: 99-106.

Shab an i R., Nosrat i M., J a vand el F., Gothbi A.A.A., Ki ou marsi H. (2012). The effect of probiotics on growth performance of broilers. Ann. Biol. Res., 3: 5450-5452.

S h a s h idh ar a R.G., D e v e g ow d a G. (2003). Effect of dietary oligosaccharide on broiler breeder production traits and immunity. Poultry Sci., 82: 1319-1325.

S ła w iń s k a A., S i w e k M., B e d n a r c z y k M. (2014 a). Effects of synbiotics injected in ovo regulate immune-related gene expression in adult chickens. AJVR, 75: 997-1003.

Sławińska A., Siwek M., Żylińska J., B ardowski J., Brzezińska J., Gulewicz K., Nowak M., Urban ow ski M., Płowie c A., B ed narczyk M. (2014 b). Influence of synbiotics delivered in ovo on the immune organs development and structure. Folia Biol. (Kraków), 62: $277-285$.

S mirnov A., Tako E., Ferket P.R., Uni Z. (2006). Mucin gene expression and mucin content in the chicken intestinal goblet cells are affected by in ovo feeding of carbohydrates. Poultry Sci., 85: 669-673.

S w a m y M.N., U pendra H A. (2013). Growth performance, crude protein, ether extract and total ash in the breast muscle of broiler chickens supplemented with probiotics. Int. J. Sci. Environ. Technol., 2: 1000-1007.

Śli że w ska K., B i ern as i a k J., L i b u d z is z Z. (2006). Probiotics as an alternative to antibiotics (in Polish). Zesz. Nauk. Politechniki Łódzkiej. Chem. Spoż. Biotechnol., 984: 79-91.

Św i ąt ki ew ic z S., Ko releski J. (2007). Feed additives enhancing immune responses in poultry. Med. Weter., 63: 1291-1295. 
Tellez G., Higgins S.E,, Donoghue A.M., Harg is B.M. (2006). Digestive physiology and the role of microorganisms. J. Appl. Poultry Res., 15: 136-144.

Uni Z., N oy Y., Sklan D. (1996). Developmental parameters of the small intestine in heavy and light strain chick pre and post-hatch. Brit. Poultry Sci., 36: 63-71.

Un i Z., Gan ot S., Sklan D. (1998). Post-hatch development of mucosal function in the broiler small intestines. Poultry Sci., 77: 75-82.

Un i Z., N o y Y., S k la n D. (1999). Posthatch development of small intestinal function in the poult. Poultry Sci., 78: 215-222.

Un i Z., Tak o E., G a l- G a r b e r O., S k l a n D. (2003 a). Morphological, molecular, and functional changes in the chicken small intestine of the late-term embryo. Poultry Sci., 82: 1747-1754.

Uni Z., S mirnov A., Sklan D. (2003 b). Pre- and posthatch development of goblet cells in the broiler small intestine: effect of delayed access to feed. Poultry Sci., 82: 320-327.

Villaluenga C.M., Wardeńska M., Pilarski R., Bednarczyk M., Gulewicz K. (2004). Utilization of the chicken embryo model for assessment of biological activity of different oligosaccharides. Folia Biol. (Kraków), 52: 135-142.

Wille m s O.W., Mille r S.P., Wo o d B.J. (2013). Aspects of selection for feed efficiency in meat producing poultry. World's Poultry Sci. J., 69: 77-87.

$\mathrm{X}$ i a o fe i H., Yu m ing G. (2008). Corticosterone administration after small intestine morphology and function of broiler chickens. Asian-Aust. J. Anim. Sci., 21: 1773-1778.

Xu Z.R., Hu C.H., Xi a M.S., Zhan X.A., Wang M.Q. (2003). Effects of dietary fructooligosaccharide on digestive enzyme activities, intestinal microflora and morphology of male broilers. Poultry Sci., 82: 1030-1036.

Yadav G.B., Kadam A.S., Pachpande A.M., L a mbate S.B., Lonkar V.D., Maini S., R a vikanth K. (2010). Post hatch histo-morphological studies of small intestinal development in chicks fed with herbal early chick nutritional supplement. Int. J. Poultry Sci., 9: 851-855.

Ya m a u ch i K., Tar a c ha i P. (2000). Change in intestinal villus, cell area and intracellular autophagic vacuoles related to intestinal function in chickens. Br. Poultry Sci., 41: 116-123

Ya m a u c hi K., I n c ha r o en T., Ya m a u ch i K. (2010). The relationship between intestinal histology and function as shown by compensatory enlargement of remnant villi after midgut resection in chickens. Anat. Rec., 293: 2071-2079.

Yang H.M., Wang W., Wang Z.Y., Wang J., C a o Y.J., C hen Y.H. (2013). Comparative study of intestine length, weight and digestibility on different body weight chickens. Afr. J. Biotechnol., 12: 5097-5100.

Yus rizal Y., Chen T.C. (2003). Effect of adding chicory fructans in feed on broiler growth performance, serum cholesterol and intestinal length. Int. J. Poultry Sci., 2: 214-219.

Zavarize K., Sartori J., Gonzales E., Pezzato A. (2012). Morphological changes of the intestinal mucosa of broilers and layers as affected by fasting before sample collection. Braz. J. Poultry Sci., 14: 21-25.

Zhai W., Gerard P.D., Pulikanti R., Peebles E.D. (2011 a). Effects of in ovo injection of carbohydrates on embryonic metabolism, hatchability, and subsequent somatic characteristics of broiler hatchlings. Poultry Sci., 90: 2134-2143.

Zha i W., Rowe D.E., P e e ble s E.D. (2011 b). Effects of commercial in ovo injection of carbohydrates on broiler embryogenesis. Poultry Sci., 90: 1295-1301.

Received: 1 IV 2016

Accepted: 19 VII 2016 